\title{
Impact of Tobacco Smoking Status on Morbidity and Mortality in Patients Hospitalized with COVID- 19 Pneumonia: Observational study
}

Gustavo Fernandez Romero ( $\square$ gustavo.fernandezromero@tuhs.temple.edu )

Lewis Katz School of Medicine at Temple University

Eduardo Dominguez-Castillo

Lewis Katz School of Medicine at Temple University

Matthew Zheng

Lewis Katz School of Medicine at Temple University

Ibraheem Yousef

Lewis Katz School of Medicine at Temple University

Melinda Darnell

Lewis Katz School of Medicine at Temple University

Andrew Ganghemi

Lewis Katz School of Medicine at Temple University

\section{Zack Dorey-Stein}

Lewis Katz School of Medicine at Temple University

Massa Zantah

Lewis Katz School of Medicine at Temple University

Ryan Townsend

Lewis Katz School of Medicine at Temple University

\section{Catherine Myers}

Lewis Katz School of Medicine at Temple University

\section{Tse-Shuen Ku}

Lewis Katz School of Medicine at Temple University

\section{Maulin Patel}

Lewis Katz School of Medicine at Temple University

\section{Nicole Patlakh}

Lewis Katz School of Medicine at Temple University

\section{Michael Jacobs}

Lewis Katz School of Medicine at Temple University

\section{Huaqing Zhao}

Lewis Katz School of Medicine at Temple University

Rohit Gupta 
Lewis Katz School of Medicine at Temple University

\section{Parth Rali}

Lewis Katz School of Medicine at Temple University

Gerard Criner

Lewis Katz School of Medicine at Temple University

\section{Research Article}

Keywords: COVID-19, smoking, pneumonia, tobacco

Posted Date: November 14th, 2020

DOI: https://doi.org/10.21203/rs.3.rs-107391/v1

License: (9) This work is licensed under a Creative Commons Attribution 4.0 International License. Read Full License 


\section{Abstract}

Background: Determine the impact of tobacco smoking status on patients hospitalized with COVID-19 pneumonia in the need for ICU care, mechanical ventilation and mortality.

Methods: We performed a retrospective cohort study, that involved chart review. All adults 18 years or older with a diagnosis of COVID-19 pneumonia hospitalized from March 15 $5^{\text {th }}, 2020$ to May $06^{\text {th }}, 2020$ with a positive reverse transcription polymerase chain reaction (RT-PCR) nasopharyngeal swab for COVID-19. We used chi-squared test for categorical variables and student t-tests or Wilcoxon rank sum tests for continuous variables. We further used adjusted and unadjusted logistic regression to assess risk factors for mortality and intubation.

Results: Among 577 patients hospitalized with COVID-19 pneumonia, $268(46.4 \%)$ had a history of smoking including 187 former and 81 active smokers. The former smokers when compared with nonsmokers were predominantly older with more comorbidities. Also, when compared with never smokers $D$ Dimer levels were elevated in active $(p=0.05)$ and former smokers $(p<0.01)$. The former smokers versus non-smokers required increased need for advanced non-invasive respiratory support on admission $(p<0.05)$, ICU care $(p<0.05)$ and had higher mortality [1.99 (CI 95\% 1.03-3.85, $p<0.05)]$. Active smokers versus non-smokers received more mechanical ventilation [OR $2.11(\mathrm{Cl} 95 \%$ 1.06-4.19, $\mathrm{p}<0.05)$ ].

Conclusions: In our cohort of hospitalized patients with COVID-19 pneumonia, former smokers had higher need for non-invasive respiratory support on admission, ICU care, and mortality compared to nonsmokers. Also, active smokers versus non-smokers needed more mechanical ventilation.

\section{Background}

SARS-CoV-2 infection can cause pneumonia which can lead to severe hypoxemic respiratory failure. [1] Cytokine storm is the hallmark feature of severe COVID-19 along with a hypercoagulable state mediated by tissue factor expression causing systemic microthrombi. [2,3] Tobacco smoking has been reported to increase the risk of lung infections by causing structural damage to the respiratory tract, impairing the immune response and inciting lung inflammation (TNF-a, IL-1, IL-6, IL-8 and granulocyte-macrophage colony-stimulating factor). $[4,5]$ The same cytokines have been reported to have a role in the hyperinflammatory response seen in COVID-19 pneumonia. [2,3] Tobacco smoking has been associated with increased fibrinogen levels and creating a prothrombotic state. [6] In a Chinese case series of COVID19 patients, there was a trend towards higher risk for severe disease and progression on current and former smokers when compared to nonsmokers. $[7,8]$ Tobacco smoking may potentially increase the severity of COVID-19 pneumonia leading to more hypoxemia requiring more intensive respiratory support and greater mortality. However, the impact of tobacco smoking on the outcomes of patients with COVID19 pneumonia needs to be fully investigated. Herein, we report the impact of current and former tobacco smoking on the requirement for ICU care, mechanical ventilation and mortality of hospitalized patients with COVID-19 pneumonia. 


\section{Methods}

Patient population:

We performed a retrospective cohort study of all adults 18 years or older with a diagnosis of COVID-19 pneumonia hospitalized at Temple University Hospital COVID-19 from March $15^{\text {th }}, 2020$ to May $06^{\text {th }}$, 2020.

Diagnosis of COVID-19 Pneumonia:

The diagnosis of patients with COVID-19 pneumonia was based on symptoms, presence of infiltrates on chest X-ray or high-resolution CT scan (HRCT) with a positive reverse transcription polymerase chain reaction (RT-PCR) nasopharyngeal swab for SARS-CoV-2. Patients admitted to Temple University Hospital with possible COVID-19 pneumonia had a HRCT upon admission. HRCT findings were categorized based on the Radiological Society of North America expert consensus for COVID-19. [9]

All of those with negative RT-PCR for COVID-19 test were excluded. The study was approved by the Temple University Institutional Review Board (Protocol number 26854).

Determination of smoking status:

Patients were categorized in three groups based on their smoking history. Patients who never smoked were categorized as non-smokers, those who reported everyday smoking up until their admission as active smokers and those with a remote history of smoking as former smokers. The calculation of packs per year was made based on the number of cigarettes per day and years of smoking reported by the subjects.

Clinical Variables:

The clinical variables recorded included age, sex, race, body mass index (BMI), presenting symptoms, oxygen requirements, comorbidities, smoking status, history of cancer, absolute lymphocyte count, platelet count, inflammatory markers (CRP), D-dimer, ferritin. Correlations were made between clinical variables, smoking status and the need for mechanical ventilation, intensive care and mortality.

Primary outcomes:

The primary objective was to understand the effect of smoking on morbidity, need for intensive care, mechanical ventilation and mortality. Secondary objectives included the impact of smoking on need for advanced non-invasive respiratory support such as high flow nasal therapy (HFNT) and bilevel positive airway pressure (BiPAPÔ).

Statistical Analysis: 
We used chi-squared test for categorical variables and student t-tests or Wilcoxon rank sum tests for continuous variables. We further used adjusted and unadjusted logistic regression to assess risk factors for mortality and intubation. $P$ values $<0.05$ were considered significant. Statistical analysis was performed using SAS 9.4 (SAS Institute Inc., Cary, NC).

\section{Results}

A total of 577 patients were admitted to our institution with COVID-19 from March $15^{\text {th }}, 2020$ to May $06^{\text {th }}$, 2020 and are included in the analysis. Based on smoking status, there were 309 (53.5\%) nonsmokers, 187 (32.4\%) former smokers with a median pack-years of 21.7 (IQR 12.3-40) and 81 (14\%) active smokers with a median of 20 pack-years (IQR 10.8-35), Table 1 shows the demographics, clinical, laboratory and hospitalization characteristics on the patients comparing nonsmokers to former and active smokers.

Patient demographics:

The mean age was $59 \pm 16$ years for the study population, former smokers were older compared to nonsmokers and active smokers. There was no gender predominance across the groups. African Americans ( $A A$ ) were the predominant race; the number of AA active and former smokers was higher compared to AA nonsmokers $(p<0.0001)$. Mean BMI was $31.5 \pm 7.8$ with no differences between the groups.

Comorbidities:

Hypertension (66.5\%), obesity (48.5\%), diabetes (42.2\%) and psychiatric disorders (21.6\%) were the most common comorbidities detected. Compared to nonsmokers, former smokers had significantly more comorbidities such as hypertension, diabetes, coronary artery disease, heart failure, COPD, psychiatric disorder and substance abuse. Active smokers were less obese, and had a greater percentage of patients with a history of COPD, psychiatric disorder and polysubstance abuse when compared to none smokers. Former smokers when compared to active smokers had a greater reported history of cardiometabolic and cerebrovascular disease (Table 2. Supplementary file).

Biomarkers of inflammation:

In never smokers the median D Dimer was $722.5 \mathrm{ng} / \mathrm{mL}$ (IQR: $450-1172 \mathrm{ng} / \mathrm{mL}$ ) when compared to former smokers $1074.5 \mathrm{ng} / \mathrm{mL}$ (IQR: $578-2077 \mathrm{ng} / \mathrm{mL})(\mathrm{p}<0.0001)$ and active smokers $931.5 \mathrm{ng} / \mathrm{mL}$ (IQR: 475 $2043 \mathrm{ng} / \mathrm{mL})(p=0.05)$ was significantly elevated. CRP and ferritin values were not significantly different.

Oxygen requirements and intubation:

When comparing the oxygen requirements on an ordinal scale at admission, former smokers had a higher need for HFNT and BiPAPÔ compared to nonsmokers. (Table 3. Supplementary file) 
Active smokers had higher rates of mechanical ventilation when compared to nonsmokers upon admission (6.1\% versus $2.7 \%, p=0.16)$ and during hospitalization $(19.8 \%$ versus $10.4 \%, p=0.010)$. A subanalysis of mechanically ventilated active smokers $(n=16)$ showed that apart from COVID-19, there were other factors leading to mechanical ventilation such as drug abuse, encephalopathy or alcohol withdrawal in 7 patients (43\%), pulmonary edema or ineffective dialysis in $2(12.5 \%)$, metastatic malignancy in $2(12.5 \%)$ and suicidal attempt in $1(6.25 \%)$.

In a regression analysis model performed, there was a greater need for intubation in active smokers during hospitalization, odds ratio (OR) 2.09 ( $\mathrm{Cl}$ 95\% 1.05-4.15, p<0.05) when compared to nonsmokers. In former smokers, even though there was a higher risk, the difference was not statistically significant, OR $1.46(\mathrm{Cl} 95 \%$ 0.84-2.55, $\mathrm{p}=0.17)$. (Table 4)

ICU care:

A total of $155(26.8 \%)$ of all patients required ICU care. There was a significant increase in the need for ICU care in former smokers when compared to nonsmokers (32.1\% versus $22.7 \%, p<0.05)$. Active smokers had a slight increase in the need for ICU care when compared to nonsmokers (30.8\% versus $22.7 \%$, $\mathrm{p}=0.191)$, but this was not significant.

Mortality:

A total of $52(9 \%)$ patients died at the time of data analysis. There was a significant increase in deaths in former smokers compared to nonsmokers $(14.4 \%$ versus $7.2 \%, p<0.05)$ and to active smokers $(14.4 \%$ versus $3.2 \%, p<0.05$ ). Active smokers had a lower mortality compared to nonsmokers ( 3.2 versus $6.7 \%$, $\mathrm{p}=0.264$ ) but this was not significant.

On our regression analysis, former smokers had higher mortality with an OR of 1.99 (Cl 95\% 1.03-3.85, $p<0.05)$ compared to nonsmokers. There was no increased risk of mortality for active smokers when compared to nonsmokers OR of 0.53 (CI95\% 0.15-2.03, $\mathrm{p}<0.05)$. The presence of malignancy, age more than 65 years, chronic kidney disease, respiratory rate greater than 20 on admission and absolute lymphocyte count less than 1000 per mm3 were associated with higher mortality. (Table 5)

\section{Discussion}

This retrospective observational study of patients hospitalized with COVID-19 pneumonia describes the relationship between active and former smokers and their outcomes compared to nonsmokers. In our population, former smokers required more advanced non-invasive respiratory support on admission, ICU level of care during hospitalization, and had higher mortality when compared to nonsmokers hospitalized with COVID 19 pneumonia. Active smokers versus nonsmokers were found to have a higher need for mechanical ventilation with no differences in ICU care or mortality. Active smokers had a lower mortality when compared to former smokers. 
Former smokers' outcomes in our study are comparable to some of the published studies on COVID-19 pneumonia. Data from Guan et al shows that smokers had a trend towards higher risk for severe COVID19 pneumonia. Out of the 1099 patients they studied from multiple hospitals in China, 1085 had smoking status noted and the proportion of smokers (active or former) was higher in severe disease $(16.9 \%$ of patients in severe group were smokers, $5.2 \%$ were former smokers compared with $11.8 \%$ and $1.3 \%$ in the non-severe disease group respectively). More smokers met the primary composite end point of ICU admission, mechanical ventilation, or death (16 (25.8\%) vs $120(11.8 \%)$ current smokers and $5(7.6 \%)$ vs 16 (1.6\%) former smokers). [7] Liu and colleagues showed that smoking (former or current) was associated with a OR 14.2 (CI 95\%1.57-25.0) for disease progression on multivariate logistic analysis in a Chinese population of 78 patients who were assessed at 2-week after hospitalization. [13] ACE2 receptor is the cellular entry point of SARS-CoV-2 and is found abundantly in lung epithelial cells. [10,11] A recent report showed that in former smokers, there was a significantly higher gene expression of ACE2 compared to nonsmokers' lungs, therefore this population could be more susceptible to this infection. [12] Our study strengthens the impact of smoking on COVID-19 in a large urban U.S. hospital.

A greater number of comorbidities in COVID-19 patients has been associated with worse outcomes in a large study from China. [14] Richardson et al, published the largest to date population study of patients admitted with COVID-19 in New York City, describing hypertension, diabetes and obesity as their more common comorbidities, of the patients who died, diabetes was associated with a higher risk of intubation and ICU care. [15] Similar to our study, the percentage of comorbidities was much higher than the one reported in the Chinese population. Tobacco smoking has multiple attributable cardiovascular, cerebrovascular, pulmonary and oncologic diseases, and in our cohort with a higher rate of smokers this might contribute to the reported prevalence of comorbidities. [16]

Former smokers were found to have higher oxygen requirements on admission requiring the use of advanced non-invasive respiratory support (HFNT/BiPAP), this could be due to a higher prevalence of patients with COPD, structural lung disease and airflow obstruction. [17] High flow nasal oxygen and noninvasive positive pressure ventilation have been proposed to decrease the need for intubation in selected patients with COVID19 pneumonia. [1,18]

Active smokers had a similar age compared to nonsmokers, with no difference in mortality. We observed that the need of intubation was higher in active smokers, this might be related to the airway, lung parenchymal inflammation and injury caused by smoking adding to the mechanisms of respiratory failure related to SARS-CoV-2 infection. [4] Drug abuse was a contributing factor in a significant proportion of our active smokers' requiring intubation. Individuals with substance abuse disorders smoke tobacco at higher rates. [19] Even though mechanical ventilation is rarely needed for the management of 
drug overdose, the presence of obstructive lung disease increases the risk [20], it is possible that the respiratory failure caused by COVID-19 pneumonia is also a risk factor of intubation in these patients.

Active smokers in our cohort had lower mortality compared to former smokers this was most likely related to the age difference between the groups (mean age was 56.3 versus 64.5 years, $p<0.001$ ) with 92 (49.5\%) of the former smokers being older than 65 years compared to $22(27.2 \%)$ of the active smokers. The case fatality worldwide on patients with COVID-19 pneumonia has been higher in the older age distribution. [21] Also the presence of comorbidities in the former smokers compared to active smokers was higher particularly cardiovascular and cerebrovascular disease. Cigarette smoking predisposes cardiovascular disease by prompting early atherosclerosis, platelet activation, inflammation, endothelial injury and dysfunction. [22]

D-Dimer level at admission has been related to increased mortality in patients admitted with COVID-19, [23.24] in our study active and former smokers had a significantly higher D-dimer compared to nonsmokers. In prior studies from smokers and inflammatory biomarkers of cardiovascular disease risk, D dimer was not found to be elevated. [25] This correlation with the hypercoagulable state in COVID-19 patients and smokers should be further studied. Tobacco smoke leads to oxidative stress with increased mucosal inflammation and expression of inflammatory cytokines, and has also been related to increased fibrinogen levels and induce a hypercoagulable state. $[4,6]$ It is unclear what factors trigger severe pneumonia in patients infected with SARS CoV-2, two of the major proposed pathophysiologic mechanisms include hyperinflammation associated with high levels of cytokines, and a hypercoagulable state mediated by the expression of tissue factor and microthrombi formation. [2,3] Tobacco smoke could increase the risk of severe COVID 19 pneumonia by potentiating these mechanisms.

Our study strength includes that we present the highest number of current and former smokers (46.4\%) compared to other COVID-19 studies to date from either China or the US (14-15\%). [7,14] The study was limited by retrospective design with chart review for data collection. A more detailed smoking history in all subjects and capturing of pre-existing symptoms of possible undiagnosed lung disease would strengthen future studies.

\section{Conclusion}

In our cohort of patients hospitalized with COVID-19 pneumonia, former smokers had higher need for non-invasive respiratory support on admission, ICU care during hospitalization, and mortality compared to non-smokers. Active smokers versus non-smokers required more mechanical ventilation. 


\section{Abbreviations}

SARS-CoV 2: Severe acute respiratory ayndrome Coronavirus 2

COVID-19: Coronavirus Disease 2019

ICU: intensive care unit

RT-PCR: reverse transcription polymerase chain reaction

HRCT: high-resolution computed tomography scan

BMI: Body mass index

CRP: C reactive protein

AA: African Americans

IQR: Interquartile range

HFNT: high flow nasal therapy

BiPAP: bilevel positive airway pressure

NIMV: Noninvasive Mechanical Ventilation

\section{Declarations}

Ethics Approval:

The study was approved by the Temple University Institutional Review Board (Protocol number 26854)

Availability of data and approval:

The datasets used and/or analyzed during the current study are available from the corresponding author on reasonable request.

Competing interests

The authors declare that they have no competing interests. 
Funding:

This study had no funding source

Author's contributions:

GFR and GJC are responsible for full manuscript. GFR, ED, MZ, IY, AG, MD, MZ, CM, TK, ZD, RT, MP, NP were responsible for data collection. GFR, PR, RG, MJ and GJC were responsible for the methods and edition. $\mathrm{HZ}$ is responsible of the statistical analysis.

Acknowledgement:

Temple Research Consortium and all the Temple University Hospital personnel taking care of the hospitalized patients with COVID-19.

\section{References}

1. Berlin D, Gulick R, Martinez F. Severe-COVID19. NEJM. May, 15, 2020.

2. Ye Q, Wang B, Mao J. The pathogenesis and treatment of the 'Cytokine Storm' in COVID-19. J Infect. Forthcoming 2020.

3. Merad, M., Martin, J.C. Pathological inflammation in patients with COVID-19: a key role for monocytes and macrophages. Nat Rev Immunol 20, 355-362 (2020).

4. Strzelak A, Ratajczak A, Adamiec A, Feleszko W. Tobacco smoke induces and alters immune responses in the lung triggering inflammation, allergy, asthma and other lung diseases: a mechanistic review. Int J Environ Res Public Health. 2018;15(5):1033.

5. Arcavi L, Benowitz NL. Cigarette Smoking and Infection. Arch Intern Med. 2004;164(20):2206-2216. doi:10.1001/archinte.164.20.2206.

6. Nielsen VG, Hafner DT, Steinbrenner EB. Tobacco smoke-induced hypercoagulation in human plasma: role of carbon monoxide. Blood Coagul Fibrinolysis. 2013;24(4)

7. Guan WJ, Ni ZY, Hu Y, et al. Clinical characteristics of coronavirus disease 2019 in China. N Engl J Med. 2020. doi:10.1056/NEJMoa2002032

8. Zhang JJ, Dong X, Cao YY, et al. Clinical characteristics of 140 patients infected with SARS-CoV-2 in Wuhan, China. Allergy. 2020. doi:10.1111/all.14238

9. Simpson S, Kay FU, Abbara S, Bhalla S, Chung JH, Chung M, Henry TS, Kanne JP, Kligerman S, Ko JP, Litt H. Radiological Society of North America Expert Consensus Statement on Reporting Chest CT Findings Related to COVID-19. Endorsed by the Society of Thoracic Radiology, the American College of Radiology, and RSNA. Radiology: Cardiothoracic Imaging. 2020 Mar 25;2(2):e200152. 
10. Zhou, P., Yang, X., Wang, X. et al. A pneumonia outbreak associated with a new coronavirus of probable bat origin. Nature 579, 270-273 (2020). https://doi.org/10.1038/s41586-020-2012-7

11. Zhao Y, Zhao Z, Wang Y, Zhou Y, Ma Y, Zuo W. Single-cell RNA expression profiling of ACE2, the putative receptor of Wuhan 2019-nCov. bioRxiv 2020:2020.01.26.919985.

12. Cai G. Bulk and single-cell transcriptomics identify tobacco-use disparity in lung gene expression of ACE2, the receptor of 2019-nCov. medRxiv 2020; published online Feb 28.

DOI:10.1101/2020.02.05.20020107

13. Liu W, Tao Z-W, Lei W, Ming-Li Y, Kui L, Ling Z, et al. Analysis of factors associated with disease outcomes in hospitalized patients with 2019 novel coronavirus disease. Chin Med J February 2020.

14. 14. Guan WJ, Liang WH, Zhao Y, et al. Comorbidity and its impact on 1590 patients with COVID-19 in China: a nationwide analysis. Eur Respir J. 2020;55(5):2000547. Published 2020 May 14. doi:10.1183/13993003.00547-2020

15. Richardson S, Hirsch JS, Narasimhan M, et al. Presenting Characteristics, Comorbidities, and Outcomes Among 5700 Patients Hospitalized With COVID-19 in the New York City Area. JAMA. Published online April 22, 2020. doi:10.1001/jama.2020.6775.

16. Centers for Disease Control and Prevention (US); National Center for Chronic Disease Prevention and Health Promotion (US); Office on Smoking and Health (US). How Tobacco Smoke Causes Disease: The Biology and Behavioral Basis for Smoking-Attributable Disease: A Report of the Surgeon General. Atlanta (GA): Centers for Disease Control and Prevention (US); 2010.

17. 17. Kohansal R, Martinez-Camblor P, Agustí A, Buist AS, Mannino DM, Soriano JB. The natural history of chronic airflow obstruction revisited: an analysis of the Framingham offspring cohort. Am J Respir Crit Care Med. 2009;180(1):3- doi:10.1164/rccm.200901-00470C

18. Matthay MA, Aldrich JM, Gotts JE. Treatment for severe acute respiratory distress syndrome from COVID-19. Lancet Respir Med 2020; 8:433-434.

19. Campbell BK, Le T, Andrews KB, Pramod S, Guydish J. Smoking among patients in substance use disorders treatment: associations with tobacco advertising, anti-tobacco messages, and perceived health risks. Am J Drug Alcohol Abuse. 2016;42(6):649-656. doi:10.1080/00952990.2016.1183021

20. Hua A, Haight S, Hoffman RS, Manini AF. Endotracheal Intubation after Acute Drug Overdoses: Incidence, Complications, and Risk Factors. J Emerg Med. 2017;52(1):59-65. doi:10.1016/j.jemermed.2016.07.114

21. 21. Onder G, Rezza G, Brusaferro S. Case-Fatality Rate and Characteristics of Patients Dying in Relation to COVID-19 in Italy. JAMA. 2020;323(18):1775-1776. doi:10.1001/jama.2020.4683

22. Benowitz NL. Cigarette smoking and cardiovascular disease: pathophysiology and implications for treatment. Prog Cardiovasc Dis. 2003;46(1):91-111. doi:10.1016/s0033-0620(03)00087-2

23. Tang N, Li D, Wang $X$, et al: Abnormal coagulation parameters are associated with poor prognosis in patients with novel coronavirus pneumonia. J Thromb Haemost 18:844-847, 2020.

24. Zang L, Yan X, Fan Q, et al: D-dimer levels on admission to predict in-hospital mortality in patients with Covid-19. J Thromb Haemost. April 9, 2020 (early release online). Available 
at https://doi.org/10.1111/jth.14859. Accessed April 22, 2020.

25. King CC, Piper ME, Gepner AD, Fiore MC, Baker TB, Stein JH. Longitudinal Impact of Smoking and Smoking Cessation on Inflammatory Markers of Cardiovascular Disease Risk. Arterioscler Thromb Vasc Biol 2017; 37(2):374-379.

\section{Tables}


Table 1. Clinical Characteristics of Patients Hospitalized with COVID-19 Pneumonia. Comparison between Non-smokers with Former and Active Smokers. $(n=577)$

$\begin{array}{lllllll}\text { Clinical } & \text { All } & \text { Non- } & \text { Former } & \text { p-value } & \text { Active } & \text { p-value } \\ \text { Characteristic } & \text { Patients } & \text { Smokers } & \text { Smokers } & & \begin{array}{l}\text { Smokers } \\ \end{array} \\ & (n=577) & (n=309) & (n=187) & & (n=81) & \end{array}$

Demographics

\begin{tabular}{lllllll} 
Age (years) & $59 \pm 16$ & $56.3 \pm 16.1$ & $64.5 \pm 12.9$ & $<0.0001$ & $56.4 \pm 14.3$ & 0.986 \\
\hline Male sex - no. (\%) & $317(54.9)$ & $169(54.7)$ & $97(51.9)$ & 0.541 & $51(63)$ & 0.182 \\
\hline Race & & & & & &
\end{tabular}

$\begin{array}{lllllll}\text { African Americans } & 326(56.4) & 145(46.9) & 124(66.3) & <0.0001 & 57(70.4) & <0.0001\end{array}$
(\%)

Hispanics (\%)

White race (\%)

Body Mass Index $(\mathrm{kg} / \mathrm{m} 2)$

\section{Comorbidities}

\begin{tabular}{|c|c|c|c|c|c|c|}
\hline Obesity (\%) & $280(48.5)$ & $171(55.3)$ & 78 (41.7) & 0.003 & 31 (38.3) & 0.024 \\
\hline HTN (\%) & $384(66.5)$ & $192(62.1)$ & $143(76.5)$ & 0.001 & $50(61.7)$ & 0.946 \\
\hline DM (\%) & $244(42.2)$ & $124(40.1)$ & $96(51.3)$ & 0.015 & $25(30.9)$ & 0.127 \\
\hline CAD (\%) & $82(14.2)$ & $32(10.4)$ & $41(21.9)$ & 0.0004 & $9(11.1)$ & 0.851 \\
\hline CHF (\%) & 109 (18.8) & $43(13.9)$ & $51(27.3)$ & 0.0002 & $15(18.5)$ & 0.3 \\
\hline COPD (\%) & $59(10.2)$ & $8(2.5)$ & 37 (19.7) & $<0.001$ & $14(17.3)$ & $<0.0001$ \\
\hline Asthma (\%) & $84(14.5)$ & $51(16.5)$ & $24(12.8)$ & 0.26 & $9(11.1)$ & 0.231 \\
\hline CKD (\%) & $106(18.3)$ & $54(17.5)$ & $41(21.9)$ & 0.222 & $11(13.6)$ & 0.402 \\
\hline Malignancy (\%) & $34(5.9)$ & $16(5.2)$ & $13(7)$ & 0.414 & $5(6.2)$ & 0.583 \\
\hline Drug Abuse & 80 (13.8) & $20(6.5)$ & $27(14.4)$ & 0.003 & $33(40.7)$ & $<.0001$ \\
\hline $\begin{array}{l}\text { Psychiatric } \\
\text { Disorder }\end{array}$ & $125(21.6)$ & $\begin{array}{r}46 \\
(14.9)\end{array}$ & $49(26.2)$ & 0.002 & $30(37.5)$ & $<.0001$ \\
\hline
\end{tabular}

\section{Admission Features}

$\begin{array}{lllllll}\begin{array}{l}\text { Respiratory Rate } \\ \text { (per minute) }\end{array} & 20.6 \pm 5.4 & 20.6 \pm 5.3 & 20.8 \pm 5.3 & 0.566 & 21.1 \pm 5.8 & 0.355\end{array}$

$\begin{array}{lllllll}\begin{array}{l}\text { Oxygen Saturation } \\ (\%)\end{array} & 93 \pm 8.2 & 93.6 \pm 8.3 & 92.4 \pm 8.3 & 0.129 & 93.1 \pm 7.5 & 0.631\end{array}$




\begin{tabular}{|c|c|c|c|c|c|c|}
\hline $\begin{array}{l}\text { D dimer }(\mathrm{ng} / \mathrm{mL}) \text {, } \\
\text { median (IQR) }\end{array}$ & $\begin{array}{l}869(493- \\
1569)\end{array}$ & $\begin{array}{l}722.5(450- \\
1172)\end{array}$ & $\begin{array}{l}1074.5 \\
(578-2077)\end{array}$ & $<0.0001$ & $\begin{array}{l}931.5(475- \\
2043)\end{array}$ & 0.05 \\
\hline $\begin{array}{l}\text { CRP (ng/mL), } \\
\text { (mean) }\end{array}$ & $8 \pm 7$ & $7.7 \pm 6.9$ & $8.4 \pm 7.4$ & 0.480 & $6.6 \pm 6.2$ & 0.130 \\
\hline $\begin{array}{l}\text { Ferritin (ng/mL), } \\
\text { median (IQR) }\end{array}$ & $\begin{array}{l}393(185 \\
\text { to } 856)\end{array}$ & $\begin{array}{l}461 \\
(192- \\
856)\end{array}$ & $\begin{array}{l}365(198- \\
1057)\end{array}$ & 0.673 & $\begin{array}{l}322.5 \\
(161.5- \\
767)\end{array}$ & 0.079 \\
\hline \multicolumn{7}{|l|}{ Outcomes } \\
\hline $\begin{array}{l}\text { Mechanical } \\
\text { Ventilation (\%) }\end{array}$ & $78(13.5)$ & $32(10.3)$ & $29(15.5)$ & 0.090 & $16(19.8)$ & 0.022 \\
\hline ICU Care (\%) & $155(26.8)$ & $70(22.7)$ & $60(32.1)$ & 0.021 & $24(29.6)$ & 0.191 \\
\hline Mortality (\%) & $52(9)$ & $22(7.1)$ & $27(14.4)$ & 0.008 & $3(3.7)$ & 0.264 \\
\hline
\end{tabular}




\begin{tabular}{|c|c|c|c|}
\hline Clinical Characteristic & $\begin{array}{l}\text { Former Smokers } \\
(n=187)\end{array}$ & $\begin{array}{l}\text { Active Smokers } \\
(\mathrm{N}=81)\end{array}$ & p-value \\
\hline Age (years) & $64.5 \pm 12.9$ & $56.4 \pm 14.3$ & $<0.0001$ \\
\hline Male sex - no. (\%) & $97(51.9)$ & $51(63)$ & 0.094 \\
\hline \multicolumn{4}{|l|}{ Comorbidities } \\
\hline HTN (\%) & $143(76.5)$ & $50(61.7)$ & 0.014 \\
\hline DM (\%) & $96(51.3)$ & $25(30.9)$ & 0.002 \\
\hline CAD (\%) & $41(21.9)$ & $9(11.1)$ & 0.037 \\
\hline $\mathrm{CHF}(\%)$ & $51(27.3)$ & $15(18.5)$ & 0.127 \\
\hline COPD (\%) & 37 (19.7) & $14(17.3)$ & 0.632 \\
\hline Cerebrovascular Disease (\%) & $24(12.8)$ & $4(4.9)$ & 0.052 \\
\hline Malignancy (\%) & $13(7)$ & $5(6.2)$ & 0.815 \\
\hline Drug Abuse & $27(14.4)$ & $33(40.7)$ & $<0.0001$ \\
\hline Psychiatric Disorder & $49(26.2)$ & $30(37.5)$ & 0.064 \\
\hline \multicolumn{4}{|l|}{ Outcomes } \\
\hline Mortality (\%) & $27(14.4)$ & $3(3.7)$ & 0.010 \\
\hline Mechanical Ventilation (\%) & $29(15.5)$ & $16(19.8)$ & 0.393 \\
\hline ICU Care (\%) & $60(32.1)$ & $24(29.6)$ & 0.691 \\
\hline
\end{tabular}




\begin{tabular}{|c|c|c|c|c|c|c|}
\hline $\begin{array}{l}\text { Clinical } \\
\text { Characteristic }\end{array}$ & $\begin{array}{l}\text { All } \\
\text { Patients } \\
(n=577)\end{array}$ & $\begin{array}{l}\text { Non- } \\
\text { Smokers } \\
(n=309)\end{array}$ & $\begin{array}{l}\text { Former } \\
\text { Smokers } \\
(n=187)\end{array}$ & $\begin{array}{l}\mathrm{p}- \\
\text { value }\end{array}$ & $\begin{array}{l}\text { Active } \\
\text { Smokers } \\
(n=81)\end{array}$ & $\begin{array}{l}\mathrm{p} \text { - } \\
\text { value }\end{array}$ \\
\hline \multicolumn{7}{|l|}{ At Admission } \\
\hline Room Air & $\begin{array}{l}300 \\
(51.9)\end{array}$ & $168(54.4)$ & $92(49.2)$ & 0.264 & $40(49.4)$ & 0.423 \\
\hline Nasal Canula & $\begin{array}{l}188 \\
(32.5)\end{array}$ & $101(32.7)$ & $60(32.1)$ & 0.674 & $27(33.3)$ & 0.912 \\
\hline HFNT/NIMV & $70(12.1)$ & $31(10)$ & $30(16)$ & 0.048 & $9(11.1)$ & 0.775 \\
\hline $\begin{array}{l}\text { Mechanical } \\
\text { Ventilation }\end{array}$ & $19(3.2)$ & $9(2.9)$ & $5(2.7)$ & 0.876 & $5(6.1)$ & 0.16 \\
\hline \multicolumn{7}{|c|}{ Maximal respiratory support during hospitalization } \\
\hline Room Air & $\begin{array}{l}173 \\
(29.9)\end{array}$ & $92(29.8)$ & $55(29.4)$ & 0.932 & $27(33.3)$ & 0.536 \\
\hline Nasal Canula & $\begin{array}{l}222 \\
(38.4)\end{array}$ & $127(41.1)$ & $67(35.8)$ & 0.244 & $27(33.3)$ & 0.203 \\
\hline HFNT/NIMV & $\begin{array}{l}105 \\
(18.2)\end{array}$ & $58(18.8)$ & 36 (19.3) & 0.895 & $11(13.6)$ & 0.276 \\
\hline $\begin{array}{l}\text { Mechanical } \\
\text { Ventilation }\end{array}$ & 77 (13.3) & $32(10.4)$ & 29 (15.5) & 0.090 & 16 (19.8) & 0.022 \\
\hline ECMO & $5(0.8)$ & $3(0.9)$ & $2(1)$ & 0.915 & 0 & 0.376 \\
\hline
\end{tabular}


Table 4. Logistic Regression and Odds ratios for Intubation ( $N=577)$

Variable

Odds ratio $(95 \% \mathrm{Cl}) \quad \mathrm{p}$-value

Active Smoker

$2.09(1.05-4.15)$

0.034

Former Smoker

$1.46(0.84-2.55)$

0.17

Chronic Kidney Disease

$2.01(1.22-3.31)$

0.006

Respiratory rate more or equal to 20 per minute

$3.26(1.98-5.36)$

$<0.01$

Table 5. Logistic regression and Odds ratios for Mortality ( $n=577)$

Variable Odds ratio $(95 \% \mathrm{Cl}) \quad \mathrm{p}$-value

Active Smoker

$0.53(0.14-1.95)$

0.34

Former Smoker

$1.99(1.03-3.84)$

0.038

Age more or equal to 65 years

$3.0(1.5-5.99)$

0.002

Chronic Kidney Disease

$2.43(1.22-4.85)$

0.012

Malignancy

$3.29(1.35-8.04)$

0.009

Respiratory rate more or equal to 20 per minute

$2.81(1.49-5.29)$

0.001

Absolute lymphocyte count less than 1000 per mm3

$2.05(1.06-3.99)$

0.033 